\title{
Psoriasis treatment in ayurveda \& panchakarma
}

\author{
Volume 7 Issue 2 - 2017 \\ Baldeep Kour \\ Rajiv Gandhi University of Health Sciences, India
}

\section{Introduction}

You may have heard that one should not judge a book based on its cover but reality is that Physical beauty is very important and many studies have shown that people judge each other based on their physical looks during initial encounters at least until they start to know each other well. First impression of yours comes from your looks. Good looks not just improve your personality but boosts up your morale to a great extent which increases your confidence in every work you do. You then like to be more social, more active \& even more successful. Psoriasis treatment in Ayurveda \& Panchakarma.

But if you feel you are not smart enough due to weight or dark skin colour, you are still far better \& happier than many other people who don't even have a clear skin. There are people suffering from various skin allergies, infections or even some serious disease. Some of these problems are so severe that some even lose their confidence due to the uncomfortable look they receive from other people. Their skin has either unsightly flaky patches or plaques or marks which are very much visible \& unable to hide. So, it's better to take precautions while doing any experiment with your precious skin (Figure 1). One of the most dangerous diseases among them is Psoriasis. It is most common in people under the age of 35. Psoriasis is a chronic skin infection described by emissions of shallow papules and larger patches with phenomena of constant inflammation. The Lesions more often occurs first on the Elbows, Lower Limbs \& Knees Scalp and later spread all over the body. Psoriasis is a Skin Disease that harms a person's confidence to a great extent. It is characterized by the Silvery Scales or Fish Scale like Plaques on the Skin. What actually happens is that our T-cells, a type of white blood cells, normally fights with the bacteria \& viruses present in our body but in Psoriasis, these cells starts attacking our healthy skin cells. Skin cells are easily lost \& Skin will also be dry with Itching, which is so severe that in certain patients leaking of the blood is seen commonly along with Pus and Secondary Infections.

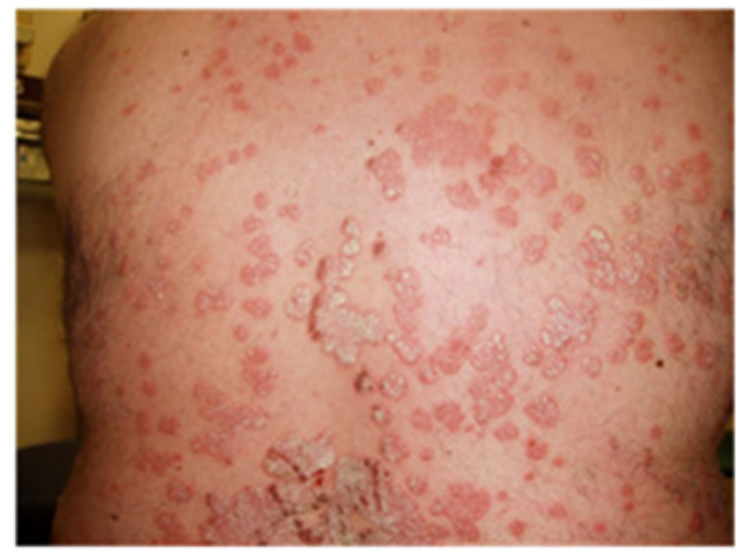

Figure I Psoriasis on chronic skin.

Generally, Psoriasis is misunderstood with Allergic Dermatitis (skin allergy) \& Seborrheic Dermatitis (head allergy like dandruff).
Without taking them as serious problem, prople start self medication or start using chemical medicines or harmful antibiotics \& drugs which just make the situation worse as the root cause of this problem are stress \& poor lifestyle because Psoriasis is an auto-immune disorder. Latest Modern Treatment for Psoriasis includes topical treatment, Injection of Steroids, Immune Suppressing Drugs etc to manage the skin conditions but the long term use of such drugs however has its own resultant complications. For a solution, psoriasis affected patients must know that timely diagnosis of the problem, a controlled, balanced \& nutritious diet along with stress free living and a well thought out Psoriasis Treatment in Ayurveda \& Panchkarma supported by yoga will be the correct \& safer path to manage and freedom from Psoriasis. According to Ayurveda, Psoriasis (Kitibh Kust) occurs due to vitiation of Vata, Kapha, Pitta \& Rakta doshas. The intake of Incompatible Food, Accumulation of Toxins etc. considered as the two of the basic energies/humors, for maintaining our body equilibrium. Aggregation of low intensity poisons (Dooshi vishas), are the main changes occurs during it in the system. Poor dietary habits, consumption of food items that can't be eaten together (dairy products with fish), over consumption of yogurt, dark gram, fish, harsh and salted things etc. can activate the pathogenesis. Liquor and tobacco utilization will act as a catalyst here. Ayurveda do emphasize on the impact of anxiety \& stress in the treatment stage of Psoriasis.

From the aspect of Ayurveda, Psoriasis Treatment in Ayurveda \& Panchkarma is done by detoxification of the body or disposal of toxic material from the body fluids which are accomplished through "Panchakarma" medications. Psoriasis majorly occurs due to vitiated pitta in the body. As liver is the seat of Pitta in Ayurveda \& body detoxification organ according to modern science, so patient is recommended to take some good herbs for liver care \& detoxification.

\section{Steps for psoriasis treatment in Ayurveda}

Step 1: First of all, blood purifiers are given to the patients to reduce increased toxins inside the body. Neem Capsule and few herbal powders \& Rishthas in classical medicines are famous for this thing.

Step 2: Secondly, emphasis moves toward liver care. Detoxification of liver is done through various therapies like Vamana / Virechana which in turn improves the immunity of the body.

Step 3: Wrong anti-biotics \& anti-histamines are avoided with the help of herbal natural medicines so as to avoid their side effects on 
various parts of our body. Deep Ayurveda has its effective herbal medicines which performs the same task as done by anti-biotics \& anti-histamines without having any side effects like Gandak Rasayan, Panchtikt Ghrit Guggul, Chander Prabha Vati etc.

Step 4: Various herbal medicated oils \& formulations have been prepared for traditional ayurvedic treatment at our all clinic having almost all the benefits like anti-allergic, anti-fungal, anti-bacterial \& anti-biotics.

Step 5: Rejuvenation of cells is done through immune boosters \& modulator herbs like Amla, Ashwagandha, Shatavari, Brahmi etc. Ayurvit Multivitamin Herbal capsules is the medicine available at Deep ayurveda for this purpose.

Step 6: At last, Ayurveda emphasizes on the proper rejuvenation, relaxation \& toning of nervous system through various neuro-tonic herbs like Brahmi, Shankhpushpi, Jatamansi, Tagar, etc. Following potent herbal medicines are very effective for this purpose:- Nervocare Herbal capsules, Brahmi Vati, Brahmi ghrit, Ashwagandha churan etc.

\section{Why ayurvedic treatment is better than various modern treatment for psoriasis?}

a. Other medicines just manage the problem for a short while, give instant relief but do not cure it permanently. These medicines have side-effects also like excessive use of them makes some bacteria \& viruses in our body irresponsive to these medicines. This in turn leads to various multi organs diseases \& in most of these cases, psoriasis ultimately leads to Rheumatic Psoriatic Arthritis \& other serious chronic condition. Whereas, Ayurveda always find the root cause of the problem \& move step wise to find the actual problem $\&$ then treat it along with proper internal healing of the body organs.

b. Other medicines have the tendency to start a vicious circle of treatments by increasing the stages of a disease. Once you take it, you'll slowly get addicted to them \& regular use of most of these medicines has its worst effect on our immune system \& metabolism. One medicine will cure a specific problem for a short while but will lead to another problem like having bad effect on liver or other organ $\&$ then again we need to take medicine for that new disorder caused. But as far as Ayurveda is concerned, finding the root cause is always the first step \& then that cause is managed $\&$ treated without having any side effect along with strengthening of that very disease prone organ. This decreases the stages of diseases \& permanently solves that problem \& indirectly Psoriasis Treatment in Ayurveda \& Panchkarma is even decreasing the chances of any future health problem by complete healing of that very organ which ensures proper functioning of it.

c. As far as a research done by Western Medical Researchers, there is not an exact cause of Psoriasis and hence it has no cure they said "when it comes to Psoriasis, Modern Medicine is absolutely inadequate". Yet our immune system \& genes can contribute to this situation \& Ayurveda do wonderful work in this case with some of its miraculous herbs to improve the immune system of the body $\&$ to provide strength to the genes \& body hormones (Figure 2).

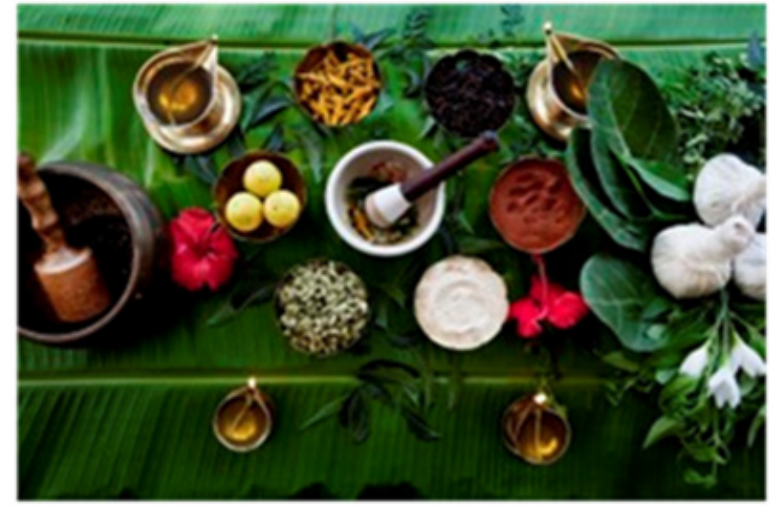

Figure 2 Herbal originated internal and external medications.

\section{Panchkarma treatment for psoriasis}

With the aim of better control on Psoriasis, Ayurveda also has a specific schedule comprised of various Panchkarma treatment aspects that includes purely herbal originated internal and external medications. A Rough idea of this complete Panchkarma treatment is as follows:

a. Consumption of medicated ghee, considering the Dosha type of the Psoriasis and the person, for 7 to 10days.

b. Vaman \& Virechan is done by inducing vomiting (Vamana) and purgation (Virechana)

c. Shirodhara the above detoxification is followed by medicated Oil or Buttermilk dripping overhead (Shirodhara) and pasting the entire body with a paste of medicines and mud.

d. Vasties (Medicated enemas)-these are being done for 8-10days and internal medicines like herbal formulations, herbal concoctions and medicated ghee need to be consumed for at least 120 to 180 days.

A strict diet regime need to be followed during the entire treatment period and it is better to continue as vegetarian diet. Non Veg, Alcohols and salted thing have to be restricted. It is better to avoid junk food also. Psoriatic must keep a state of mental calmness. At Deep Ayurveda, there are very effective Panchkarma treatment methods as well as herbal formulations for Psoriasis disease. This duration of treatment may vary from person to person, depending upon the age, body disposition, condition of the disease like its aging \& type, dietary habits and life style of the patient, etc. We have successfully treated hundreds of Psoriasis patients (Psoriasis Treatment in Ayurveda \& Panchkarma) with very good results.

\section{Acknowledgments}

None.

\section{Conflicts of interest}

Author declares there are no conflicts of interest.

\section{Funding}

None. 